\title{
Histological studies in primary neuritic leprosy: changes in the nasal mucosa
}

\author{
SUJAI SUNEETHA*, S. ARUNTHATHI*, \\ ANAND JOB\#, ANAND DATE\#, NISHA KURIAN* \& \\ CHINOY J. G. CHACKO* \\ *Schieffelin Leprosy Research and Training Centre, Karigiri, Tamil \\ Nadu-632 106, India; \#Christian Medical College and Hospital, \\ Vellore, Tamil Nadu-632 004, India
}

Accepted for publication 1 September 1998

\begin{abstract}
Summary The nasal mucosae of 39 cases of primary neuritic leprosy (PNL) registered at Karigiri were studied histologically to determine nasal mucosal involvement in PNL and its relevance to the pathogenesis of the disease. Specific changes of leprosy were seen in $20(51 \%)$ biopsies, ranging from macrophage granulomas with acid fast bacilli, to epithelioid granulomas and nerve inflammation. The remaining biopsies revealed chronic inflammatory changes of the mucosa or mild non-specific nerve changes. These findings show that there are widespread effects of the disease even in PNL patients in whom the disease is believed to be confined to the peripheral nerves. The findings also show that early leprosy involvement can be found in the nasal mucosa even before lesions become apparent in the skin or other parts of the body. The nasal mucosa could be one of the sites for the primary lesion in leprosy. Clinical and histological examination of the nasal mucosa may be useful and important in the early diagnosis of leprosy and especially in contacts.
\end{abstract}

\section{Introduction}

Although leprosy is primarily a disease of the nerves and skin, other tissues like the nasal mucosa, the anterior segment of the eye, and the testis are known to be affected by the disease. ${ }^{1}$ Involvement of the nasal mucosa in lepromatous, ${ }^{2,3}$ indeterminate, tuberculoid and borderline leprosy has been reported. ${ }^{4}$ Furthermore, studies in the nine-banded armadillo and nude mice suggest that the nasal mucosa may be an important site for entry and dissemination of lepra bacilli. ${ }^{5,6}$

Primary neuritic leprosy is characterized by signs and symptoms of a peripheral neuropathy, no recognizable skin lesions and skin smears that are negative for acid fast bacilli. $^{7}$ The pathogenesis and evolution of this form of leprosy is still poorly understood. The 
present study was undertaken to determine if there are histological changes due to leprosy in the nasal mucosa of patients with PNL and its relevance to the pathogenesis of the disease.

\section{Materials and methods}

Nasal mucosal biopsies from 39 consenting patients with PNL seen at the outpatient department at Karigiri were studied. A diagnosis of PNL was made based on the following clinical criteria; signs and symptoms of a peripheral neuropathy, absence of skin patches and negative skin smear. ${ }^{8}$ A cutaneous nerve biopsy was done in all these patients. A histological confirmation of leprosy was available in 32 patients. The remaining seven patients were treated as leprosy, based on finding definite nerve thickening and the other clinical criteria for PNL. ${ }^{9}$ Other causes of a peripheral neuropathy were excluded.

A cotton swab soaked in $2 \%$ xylocaine with adrenaline was placed in the nostril for a few minutes to produce local anaesthesia and reduce the risk of bleeding. The biopsy was taken from the mucosa over the anterior end of the inferior turbinate bone using a Takahashi nasal biopsy forcep and the specimen was immediately immersed in Formol-Zenker's fixative for $4 \mathrm{~h}$ and then transferred to $70 \%$ alcohol. It was then routinely processed and embedded in paraffin. Serial 5- $\mu \mathrm{m}$ thick sections were cut. Some sections were stained with haematoxylin and eosin and others with Job and Chacko's modification of the Fite Faraco stain for acid fast bacilli. ${ }^{10}$ The yield of diagnostic lesions in the nasal mucosa was then determined.

\section{Results}

Based on histological examination the biopsies were classified as in Table 1. A brief description of the histological changes is given below.

\section{NERVE INFLAMMATION}

Nine of the 39 nasal mucosal biopsies $(23 \%)$ showed inflamed nerves in the nasal mucosa (Table 1). The nerves were enlarged (Figure 1) and showed dense perineurial and mild intraneural infiltration by lymphocytes (Figure 2). There was usually an accompanying chronic perivascular, adnexal and subepithelial inflammation of the mucosa. Four of them $(44 \%)$ revealed acid fast bacilli in the Fite stained sections.

Table 1. Histological findings in nasal mucosa

\begin{tabular}{lcc}
\hline Histological diagnosis & No. of patients (\%) & Biopsies with AFB (\%) \\
\hline Nerve inflammation & $9(23)$ & $4(44)$ \\
Macrophage granulomas & $9(23)$ & $9(100)$ \\
Epithelioid granuloma & $2(5)$ & 0 \\
Non-specific inflammation & $19(49)$ & 0 \\
Total & 39 & 13 \\
\hline
\end{tabular}




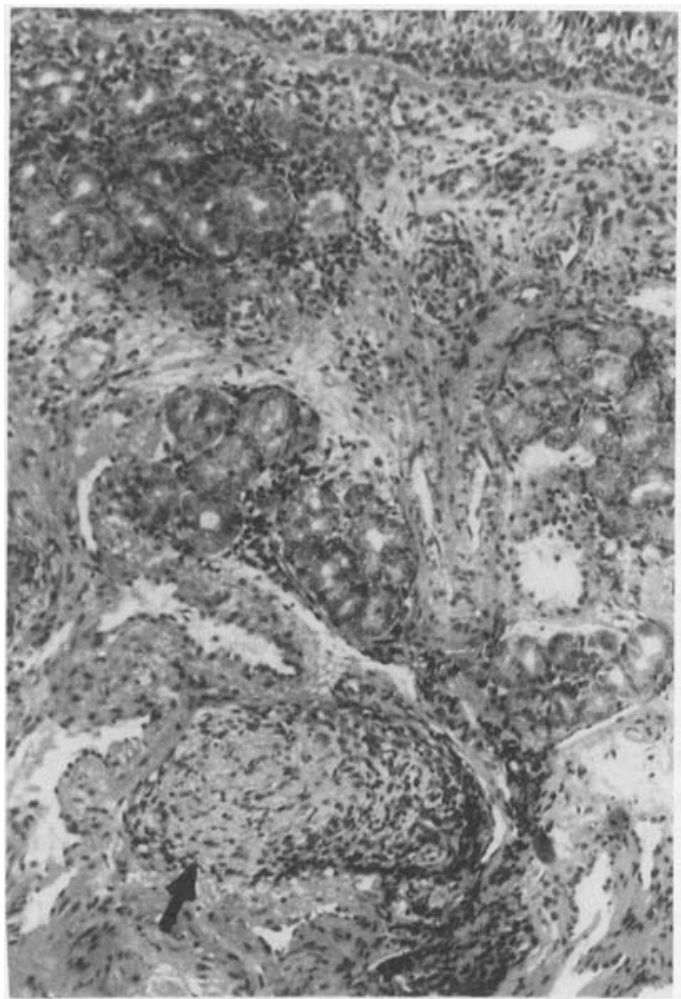

Figure 1. Photomicrograph of the nasal mucosa showing mild inflammation of the submucosa and an enlarged and inflamed nerve $(\mathrm{H} \& \mathrm{E} \times 100)$.

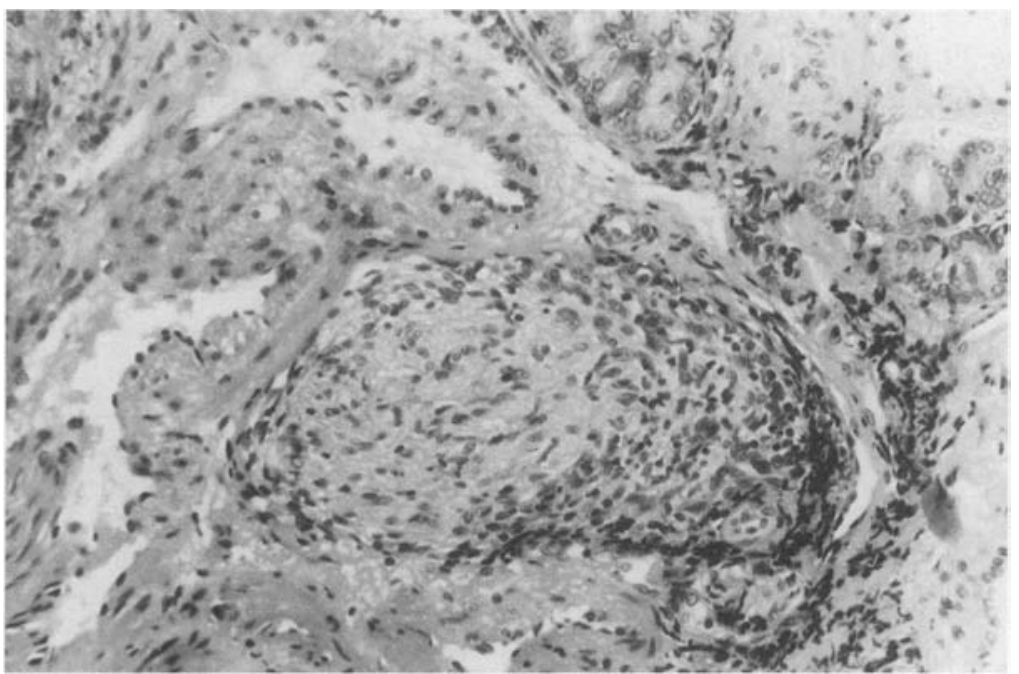

Figure 2. Closeup of the enlarged nerve showing dense intraneural lymphocytes and histiocytes $(H \& E \times 200)$. 


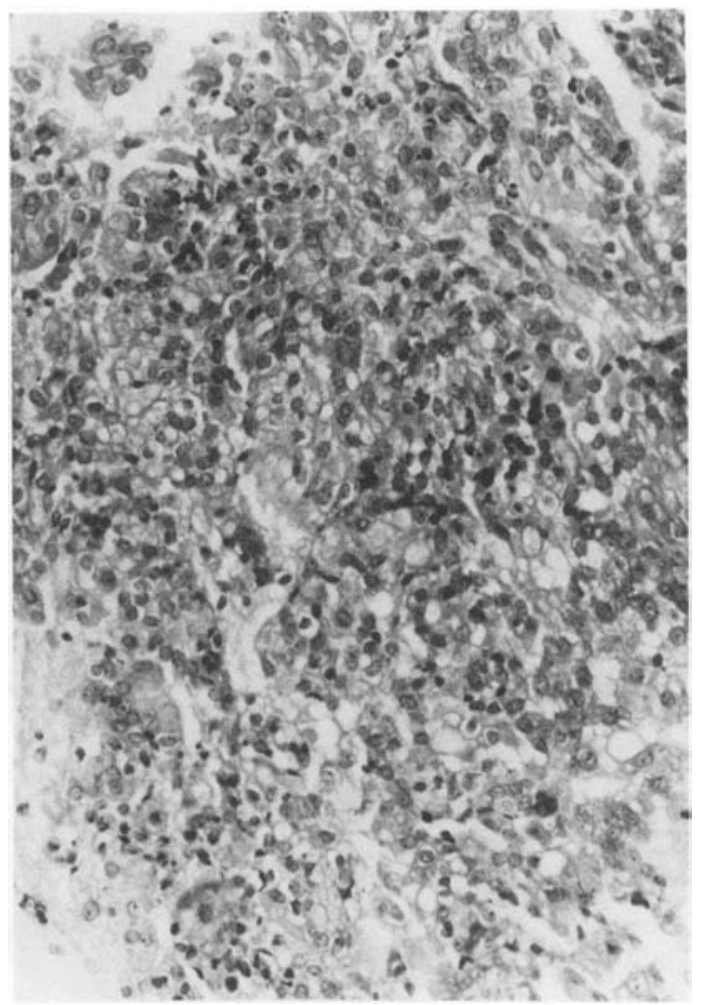

Figure 3. Photomicrograph of the nasal mucosa showing macrophages in the loose stromal connective tissue $(\mathrm{H} \& \mathrm{E} \times 400)$.

\section{MACROPHAGE GRANULOMAS}

Macrophage granulomas were seen in nine $(23 \%)$ of the biopsies. The macrophages were present in the nasal mucosa in relation to mucosal glands and in the loose stromal connective tissue (Figure 3). Fite stained sections revealed acid fast bacilli in all these nine cases, in the macrophages (Figure 4), nerves and in endothelial cells of blood vessels.

\section{EPITHELIOID GRANULOMAS}

Aggregates of epithelioid cells cuffed by lymphocytes were seen in the nasal mucosal biopsies in two patients $(5 \%)$. These epithelioid cells were present in relation to mucosal glands (Figure 5), and there was accompanying nerve inflammation and chronic inflammatory changes in the mucosa. Acid fast bacilli were not seen.

\section{NON-SPECIFIC INFLAMMATION}

Nineteen biopsies (49\%) revealed non-specific inflammatory changes in the mucosa consisting of perivascular and periglandular infiltrate of lymphocytes, histiocytes and plasma cells with no evidence of nerve inflammation or bacilli. In five of these biopsies, the nerves showed prominent Schwann cell nuclei and prominent perineurial cells. 


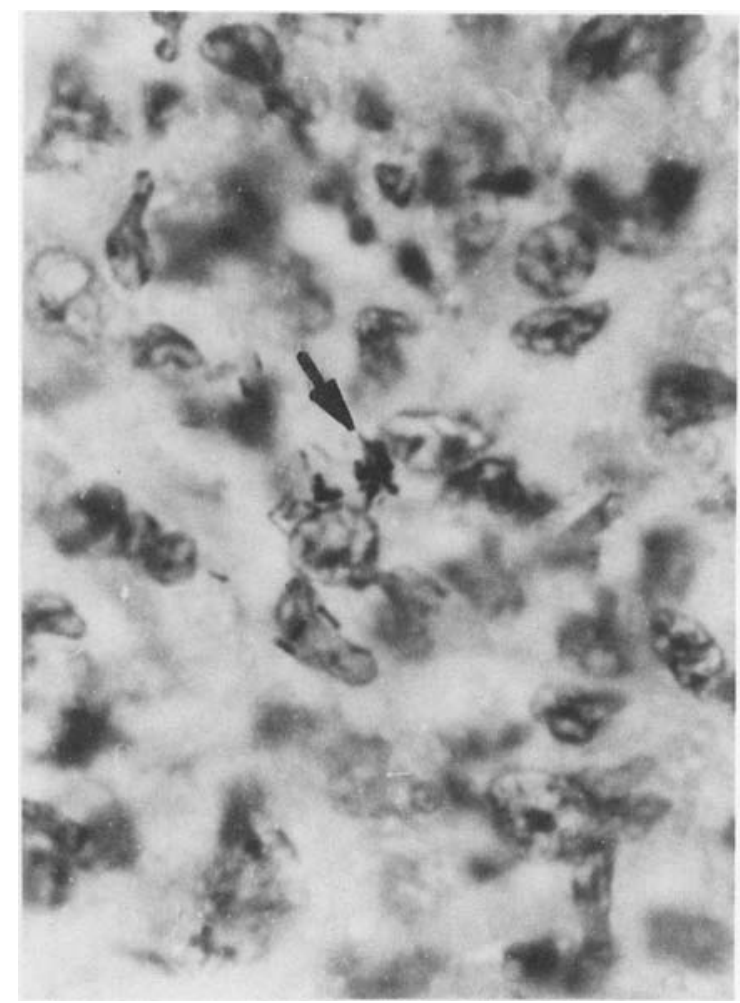

Figure 4. Acid fast stain showing clumps of bacilli in macrophages in the nasal mucosa (modified Fite's stain $\times 1000)$.

The relationship between the nasal biopsy findings and nerve histology is given in Table 2. Of the 17 patients who had a multibacillary histology [lepromatous leprosy (LL) and borderline lepromatous leprosy (BL)] in the nerve, 10 (59\%) showed nerve inflammation, acid fast bacilli or granulomas in the nasal mucosa. Among the 15 patients who showed a borderline tuberculoid (BT) or indeterminate leprosy histology in the nerve, five displayed nerve inflammation; one had a epithelioid granuloma and the majority (nine) revealed nonspecific inflammation in the nasal mucosa.

\section{Discussion}

The nasal mucosa is a rich reservoir of infection. While no organisms are shed from the intact skin of even highly bacilliferous lepromatous patients, ${ }^{11}$ large numbers of $M$. leprae are disseminated in the nasal secretions of lepromatous leprosy patients. ${ }^{2}$ These bacilli are viable and capable of multiplication in a new host. ${ }^{12}$ Therefore nasal secretions of a multibacillary patient may be a very potent, if not the only source of $M$. leprae and droplet infection is a distinct possibility. Animal studies have shown that when immunosuppressed nude mice were placed in an environment containing aerosolized $M$. leprae, they developed the disease. ${ }^{13}$ Introduction of $M$. le prae into the lung of mice by tracheostomy did not result 


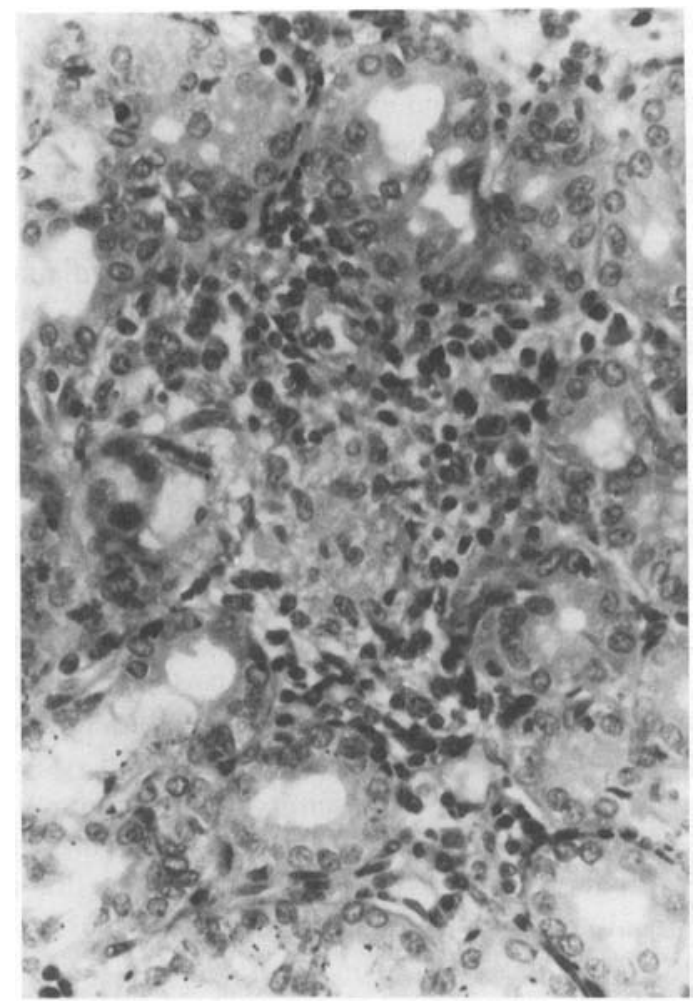

Figure 5. Photomicrograph of nasal mucosa showing a closeup of an epithelioid cell collection surrounded by lymphocytes and plasma cells $(\mathrm{H} \& \mathrm{E} \times 400)$.

in disease, whereas delivery of $M$. leprae into the nostril in a saline suspension was associated with invasion of the nasal mucosa producing a localized nodule and disseminated disease 15 months later. ${ }^{5}$ In addition, recent biochemical studies have characterized an M. leprae gene encoding a fibronectin-integrin receptor present on nasal epithelial cells resulting in internalization of the bacteria. ${ }^{14,15}$

Table 2. Relationship between nasal histological findings and nerve histology

\begin{tabular}{lcccccc}
\hline & \multicolumn{5}{c}{ Nerve biopsy diagnosis } \\
\cline { 2 - 7 } Histological findings in nasal mucosa & LL & BL & BT & Ind. Lep. & $*$ NSL & Total \\
\hline Nerve inflammation & - & 2 & 2 & 3 & 2 & 9 \\
Macrophage granulomas & 1 & 6 & - & - & 2 & 9 \\
Epithelioid granulomas & - & 1 & 1 & - & 0 & 2 \\
Non-specific inflammation & - & 7 & 1 & 11 & 7 & 39 \\
Total & 1 & 16 & 4 & & 3 \\
\hline
\end{tabular}

*NSL, no significant lesion, LL, lepromatous leprosy, BL, borderline lepromatous leprosy, Ind. Lep., indeterminate leprosy. 
In the present study, there were specific changes due to leprosy in the nasal mucosa in over half the patients, confirming that the nasal mucosa is involved in PNL. The histological finding of nerve inflammation, bacilli and even granulomas in the nasal mucosa, which is a site distant from the peripheral nerves, suggests that there are widespread effects of the disease even in PNL patients where the disease is believed to be confined to the peripheral nerves.

Nineteen patients $(49 \%)$ were found to have non-specific inflammatory changes in the mucosa. These could, in some cases, be due to a nasal smear being taken from the same site prior to the biopsy. Alternatively, the perivascular and periglandular location of the infiltrate may indicate early changes specific to leprosy. ${ }^{16}$ The prominent nerves seen in five of these patients may also be a step in the progression towards specific nerve inflammation. All these observations establish that there is a generalized infection in PNL and that the disease is not confined to the peripheral nerves. Furthermore, over $30 \%$ of these patients also revealed specific changes due to leprosy in the apparently normal skin from an area of sensory change. $^{17}$

The findings of this study are consistent with the nasal mucosa being one of the sites for the primary lesion in leprosy. From this primary focus, the organism may spread via the bloodstream and/or lymphatics to lodge in nerves, skin and other sites, where the secondary lesions occur. The findings of bacilli in endothelial cells of blood vessels and the perivascular infiltrate is consistent with haematogenous dissemination of infection.

The histological changes in the nasal mucosa, which range from epithelioid granuloma with no bacilli to macrophages with acid fast bacilli, may indicate that the factors that influence local mucosal immunity may determine the future course of the infection. ${ }^{18,19}$

All seven of the patients who revealed macrophages in the nasal mucosa had a lepromatous or borderline lepromatous nerve histology. However, one of the patients who showed epithelioid granulomas in the nasal mucosa showed borderline lepromatous features in the nerve. Such a discrepancy between skin and nerve histology in the same patients has been shown by us and others, ${ }^{20,21}$ and suggests that the nasal mucosa (like the skin) is an immunologically open site and may respond differently from nerve tissue, which is considered an immunologically privileged site. ${ }^{22}$

Interestingly, four of the seven patients who did not show any significant pathology in the nerve revealed specific changes-macrophage granulomas with acid fast bacilli (two) and nerve inflammation (two) in the nasal mucosa (Table 2). These findings could suggest that early leprosy involvement can be found in the nasal mucosa before the disease can be identified pathologically in the skin, nerve or other parts of the body. Nasal symptoms may be the first clinical manifestation of leprosy. ${ }^{3,23}$ Clinical examination and histology of the nasal mucosa may be useful and important in the early diagnosis of leprosy and especially in contacts.

More recently, a population endemic for leprosy was screened for nasal carriage of $M$. leprae using the sensitive polymerase chain reaction (PCR) technique and found $7.8 \%$ positivity. ${ }^{24}$ Its significance to infection and disease will need to be investigated. Nasal mucosal biopsies and clinical follow-up of such individuals will throw light on the significance of the bacilli in the nose, the role of nasal mucosal immunity and the possible progression of the disease.

In conclusion, the present study establishes that there is nasal mucosal involvement in PNL. The findings of nerve inflammation, bacilli and granulomas in the nasal mucosa of 
patients with PNL (even when the nerve lesion is at a site distant from the nose) suggests that there may be disseminated disease even in these patients and shows that PNL can no longer be considered as confined to peripheral nerves. Nasal mucosa could represent one of the sites for the primary lesion in leprosy. Clinical and histological examination of the nasal mucosa may be useful in the early diagnosis of the disease.

\section{Acknowledgements}

We thank Dr C. K. Job, Dr. P. S. S. S. Rao and Dr Steve Withington for their comments and suggestions during the preparation of this manuscript, and Ms Amala and Mr K. Ramana Babu for secretarial help.

\section{References}

1 Job CK. Pathology of leprosy. In: Hastings RC, ed. Leprosy, 2nd edn. Churchill Livingstone, New York, 1994: 193-224.

2 Devey TF, Rees RJW. The nasal discharge in leprosy; clinical and bacteriological aspects. Lepr Rev, 1974; 45: 121-134.

${ }^{3}$ Friedmann I, Osborn DA. The nose and nasal sinuses. In: Symmers WStC, ed. Systemic pathology, 2nd edn. Churchill Livingstone, New York, 1974: 192-235.

4 Chacko CJG, Bhanu T, Victor V, Alexander R, Taylor PM, Job CK. The significance of changes in nasal mucosa in indeterminate, tuberculoid and borderline leprosy. Lepr India, 1979; 51: 8-22.

5 Chehl S, Job CK, Hastings RC. Transmission of leprosy in nude mice. Am J Trop Med Hyg, 1985; 34: 11611166.

6 Job CK, Harris EB, Allen JL, Hastings RC. Thorns in armadillo ears and noses and their role in the transmission of leprosy. Arch Pathol Lab Med, 1986; 110: 1025-1028.

7 Pannikar VK, Arunthathi S, Chacko CJG, Fritschi EP. A clinicopathological study of primary neuritic leprosy. Ind J Lepr, 1983; 55: 212-221.

8 Noordeen SK. Epidemiology of (poly)neuritic type of leprosy. Lepr India, 1972; 44: 90-96.

9 Kaur G, Girdhar BK, Girdhar A, Malaviya GN, Mukherjee A, Sengupta U, Desikan KV. A clinical, immunological and histological study of neuritic leprosy patients. Int J Lepr, 1991; 59: 385-391.

10 Job CK, Chacko CJG. A modification of Fite's stain for demonstrations of M. leprae in tissue sections. Ind J Lepr, 1986; 58: 17-18.

11 Pedley JC. Composite skin contact smears: a method of demonstrating non-emergence of Mycobacterium leprae from intact lepromatous skin. Lepr Rev, 1970; 41: 31-43.

12 Shephard CC. Acid fast bacilli in nasal secretions in leprosy, and results of inoculation of mice. Am J Hyg, 1960; 71: $147-157$.

${ }^{13}$ Rees RJW, McDougall AC. Airborne infection with Mycobacterium leprae in mice. J Med Microbiol, 1977; 10: 63-68.

${ }^{14}$ Byrd SR, Gelber R, Bermudez LE. Roles of soluble fibronectin and $\beta 1$ integrin receptors in the binding of Mycobacterium leprae to nasal epithelial cells. Clin Immunol Immunopathol, 1993; 69: 266-271.

15 Schorey JS, Li Q, McCourt DW, Bong-Mastek M, Clark-Curtis JE, Ratliff TL, Brown EJ. A Mycobacterium leprae gene encoding a fibronectin binding protein is used for efficient invasion of epithelial cells and Schwann cells. Infect Immun, 1995; 63: 2652-2657.

16 Cerruti H. Histopathology of the nasal mucosa in leprosy. Rev Bras Leprol, 1944; 12: 309-364.

17 Suneetha S, Arunthathi S, Chandi S, Kurian N, Chacko CJG. Histological studies in primary neuritic leprosy: changes in the apparently normal skin (Communicated to Lepr. Rev).

18 Stoner GL. Hypothesis: do phases of immunosuppression during a Mycobacterium leprae infection determine the leprosy spectrum? Lepr Rev 1981; 52: 1-10.

19 Ramprasad B, Cree IA, Oluwoli M, Samson PD. Development of a mucosal challenge test for leprosy using leprosin A. J Immunol Methods, 1995; 188: 239-246.

20 Ebenezer GJ, Suneetha S, Mohandas R, Arunthathi S. Multibacillary nerve histology in clinically diagnosed borderline tuberculoid leprosy patients. Int J Lepr, 1996; 64: 311-315.

21 Srinivasan H, Rao KS, Iyer CGS. Discrepancy in the histopathological features of leprosy lesions in the skin and peripheral nerve. Report of a preliminary study. Lepr India, 1982; 54: 275-282. 
${ }^{22}$ Harboe M. Overview of host-parasitic relations. In: Hastings RC, ed. Leprosy 2nd edn. Churchill Livingstone, New York, 1994; 87-112.

${ }^{23}$ Yoshie Y. Leprosy of upper respiratory tract. Atlas of clinical picture and notes on the research. Yoshie Y., Tokyo, 1982.

${ }^{24}$ Klatser PR, Van Beers S, Madjid B, Day R, De Witt MYL. Detection of Mycobacterium leprae nasal carriers in populations for which leprosy is endemic. J Clin Microbiol, 1993; 31: 2947-2951. 